\title{
The Chitinase-Like Protein YKL-40 Modulates Cystic Fibrosis Lung Disease
}

\author{
Andreas Hector $^{19}$, Michael S. D. Kormann ${ }^{19}$, Ines Mack ${ }^{89}$, Philipp Latzin ${ }^{2}$, Carmen Casaulta ${ }^{2}$, Elisabeth \\ Kieninger ${ }^{2}$, Zhe Zhou ${ }^{3}$, Ali Ö. Yildirim ${ }^{5}$, Alexander Bohla ${ }^{5}$, Nikolaus Rieber', Matthias Kappler ${ }^{8}$, Barbara \\ Koller $^{6}$, Ernst Eber ${ }^{9}$, Olaf Eickmeier ${ }^{7}$, Stefan Zielen ${ }^{7}$, Oliver Eickelberg ${ }^{5}$, Matthias Griese ${ }^{8}$, Marcus A. \\ Mall $^{3,4}$, Dominik Hartl ${ }^{1 *}$
}

1 Department I, Children's Hospital, University of Tübingen, Tübingen, Germany, 2 Department of Paediatrics, University of Berne, Inselspital, Berne, Switzerland, 3 Division of Pediatric Pulmonology and Allergy and Cystic Fibrosis Center, Department of Pediatrics III, University of Heidelberg, Heidelberg, Germany, 4 Translational Lung Research Center, University of Heidelberg, Heidelberg, Germany, 5 Comprehensive Pneumology Center, Institute of Lung Biology and Disease (iLBD), University Hospital, Ludwig Maximilians University and Helmholtz ZentrumMünchen, Munich, Germany, 6 Department of Dermatology and Allergy, Ludwig-Maximilians-University, Munich, Germany, 7 Department of Pediatric Pulmonology, Allergy and Cystic Fibrosis, Children's Hospital, Frankfurt, Germany, 8 Research Center, Children's Hospital, LudwigMaximilians-University, Munich, Germany, 9 Respiratory and Allergic Disease Division, Paediatric Department, Medical University of Graz, Graz, Austria

\begin{abstract}
The chitinase-like protein YKL-40 was found to be increased in patients with severe asthma and chronic obstructive pulmonary disease (COPD), two disease conditions featuring neutrophilic infiltrates. Based on these studies and a previous report indicating that neutrophils secrete YKL-40, we hypothesized that YKL-40 plays a key role in cystic fibrosis (CF) lung disease, a prototypic neutrophilic disease. The aim of this study was (i) to analyze YKL-40 levels in human and murine CF lung disease and (ii) to investigate whether $Y K L-40$ single-nucleotide polymorphisms (SNPs) modulate CF lung disease severity. YKL-40 protein levels were quantified in serum and sputum supernatants from CF patients and control individuals. Levels of the murine homologue BRP-39 were analyzed in airway fluids from CF-like $\beta E N a C-T g$ mice. YKL-40SNPs were analyzed in CF patients. YKL-40 levels were increased in sputum supernatants and in serum from CF patients compared to healthy control individuals. Within CF patients, YKL-40 levels were higher in sputum than in serum. BRP-39 levels were increased in airways fluids from $\beta \mathrm{ENaC}-\mathrm{Tg}$ mice compared to wild-type littermates. In both CF patients and $\beta \mathrm{ENaC}-\mathrm{Tg}$ mice, YKL-40/BRP-39 airway levels correlated with the severity of pulmonary obstruction. Two YKL-40 SNPs (rs871799 and rs880633) were found to modulate age-adjusted lung function in CF patients. YKL-40/BRP-39 levelsare increased in human and murine CF airway fluids, correlate with pulmonary function and modulate CF lung disease severity genetically. These findings suggest YKL-40 as a potential biomarker in CF lung disease.
\end{abstract}

Citation: Hector A, Kormann MSD, Mack I, Latzin P, Casaulta C, et al. (2011) The Chitinase-Like Protein YKL-40 Modulates Cystic Fibrosis Lung Disease. PLoS ONE 6(9): e24399. doi:10.1371/journal.pone.0024399

Editor: Neeraj Vij, Johns Hopkins School of Medicine, United States of America

Received June 2, 2011; Accepted August 8, 2011; Published September 20, 2011

Copyright: (c) 2011 Hector et al. This is an open-access article distributed under the terms of the Creative Commons Attribution License, which permits unrestricted use, distribution, and reproduction in any medium, provided the original author and source are credited.

Funding: This work was supported by the German Research Foundation (DFG, Emmy Noether Programme HA 5274/3-1 to D.H., MA 2081/3-3 and MA 2081/4-1 to M.A.M.), the German Society of Pediatric Pneumology (D.H.), PINA e.V. (D.H.), the Novartis Foundation (D.H.) and the Ernest-Solvay-Foundation (D.H.). The funders had no role in study design, data collection and analysis, decision to publish, or preparation of the manuscript.

Competing Interests: The authors have declared that no competing interests exist.

*E-mail: dominik.hartl@med.uni-tuebingen.de

9 These authors contributed equally to this work.

\section{Introduction}

Chronic lung disease determines the morbidity and mortality of cystic fibrosis (CF) patients [1]. CF lung disease is characterized by a nonresolving neutrophilic inflammation with impaired antibacterial killing and proteolytic destruction of pulmonary tissue [2].

Humans lack chitin, but they express chitinases and chitinaselike proteins (CLP). Both chitinases and CLP belong to the 18glycosyl-hydrolase family, including acidic mammalian chitinase (AMCase), chitotriosidase, oviductin, YKL-40 in humans, while YM-1, YM-2, AMCase, oviductin, and breast regression protein (BRP-39) have been described in mice. CLPs bind chitin, but do not have enzymatic chitinase activity due to mutations in their highly conserved putative enzyme sites [3]. The prototypical GLP YKL-40 (YKL for the first three N-terminal residues of a $40 \mathrm{kDa}$ protein, also termed human cartilage glycoprotein (HcGP)-39) gene is localized on chromosome 1 [4]. The murine homologue of YKL-40 is breast regression protein of $39 \mathrm{kDa}$ (BRP-39). YKL40/BRP-39 was initially described to be expressed in cancer cells and several lines of evidence support the view that YKL-40/BRP39 plays a role in cell proliferation, survival and tissue remodeling [5-7].

YKL-40 protein levels are detectable in human serum and were unexpectedly found to be significantly increased in patients with severe asthma [8] and chronic obstructive pulmonary disease (COPD) [9], two disease conditions featuring neutrophilic infiltrates. Based on these studies and a previous report indicating that neutrophils secrete YKL-40 [21], we hypothesized that YKL40 plays a key role in CF lung disease, a prototypic neutrophilic disease.

We quantified YKL-40 protein levels in serum and airway fluids (sputum supernatants) from individuals with $\mathrm{CF}$ and control 
subjects without pulmonary diseases, assessed BRP-39 levels and lung function in a mouse model of CF-like lung disease $(\beta \mathrm{ENaC}$ $\mathrm{Tg}$ mice) and analyzed the impact of $Y K L-40$ gene variants on YKL-40 protein levels and age-adjusted CF lung disease severity.

\section{Materials and Methods}

\section{Patient cohorts}

In total, $338 \mathrm{CF}$ patients were included in the study (see genotyping cohort below, Methods S1 and Table S1). Out of this cohort we were able to collect both peripheral blood and induced sputum ex vivo sample material simultaneously from 59 patients in order to quantify YKL-40 protein levels. Accordingly, YKL-40 protein levels were analyzed in serum and induced sputum supernatants of patients with $\mathrm{CF}(\mathrm{n}=59)$ and healthy control subjects $(\mathrm{n}=26)$ (Table 1). The $\mathrm{CF}$ group included 31 male and 28 female patients with a mean age of $22 \pm 15(\mathrm{SD})$ years. Inclusion criteria were the diagnosis of $\mathrm{CF}$ by clinical symptoms and positive sweat tests (sweat Cl- concentration $>60 \mathrm{mmol} / \mathrm{l}$ ) or diseasecausing mutations in the CFTR gene, forced expiratory volume in 1 second (FEV1) $>30 \%$ of predicted value $[31,32]$ and being clinically stable and on steady concomitant therapy at least four weeks prior to the study. Genetically, $34 \mathrm{CF}$ patients were $\Delta \mathrm{F} 508$ homozygous, 19 were $\Delta \mathrm{F} 508$ heterozygous carriers of the CFTR gene and 6 had other CFTR mutations than $\Delta$ F508. Twenty-six control subjects without pulmonary diseases were selected as the control group (12 male, 14 female; mean age: 25 9 SD years). These subjects had no suspected or proven pulmonary disease and were free of respiratory tract infections [30]. Informed written consent was obtained from all subjects included in the study or their parents, and all study methods were approved by the local ethics committee (Ethics committee of the Ludwig-Maximilians-University (LMU), Munich, Germany) and by the institutional review board of the Children's Hospital of the Ludwig-MaximiliansUniversity, Munich, Germany. Induced sputum was obtained, processed and stored as described previously [22,33]. Cell-free sputum supernatant was stored at $-80^{\circ} \mathrm{C}$ until analysis.

\section{Experimental animals}

The generation of $\beta \mathrm{ENaC}-\mathrm{Tg}$ mice has been previously described [36]. Animal studies of the betaENaC-Tg mice (ID 6608) were approved by the Regierungspräsidium Karlsruhe or by the Regierung von Oberbayern, Munich, Germany. The colony was

Table 1. Patient groups.

\begin{tabular}{lll}
\hline & & \\
\hline & Cystic fibrosis & Controls \\
\hline $\mathrm{N}$ & 59 & 26 \\
Age [yrs] & $22 \pm 15$ & $25 \pm 9$ \\
Sex (m:f) & $31 / 28$ & $12 / 14$ \\
WBC $\left(10^{9} / \mathrm{l}\right)$ & $10 \pm 5$ & $8 \pm 3$ \\
FEV ${ }_{1}(\%$ pred) & $63 \pm 15$ & - \\
Neutrophils in sputa (\%) & $83 \pm 32$ & $17 \pm 10$ \\
P. aeruginosa† & 35 & 0 \\
Antibiotics & 35 & 0 \\
dF508homozygous/heterozygous/other & $34 / 19 / 6$ & n.d. \\
\hline
\end{tabular}

Results are expressed as means $\pm \mathrm{SD}$; $\mathrm{m}$ : male, f: female; WBC: white blood count; $\mathrm{FEV}_{1}$ : Forced expiratory volume in 1 second (\% of predicted);

${ }^{\dagger} P$. aeruginosa bacteria isolated in at least 2 consecutive sputum samples with a minimum of a 6-month interval; n.d. not determined.

doi:10.1371/journal.pone.0024399.t001 maintained on a mixed genetic background $(\mathrm{C} 3 \mathrm{H} / \mathrm{HeN} \times \mathrm{C} 57 \mathrm{BL} /$ $6 \mathrm{~N}$ ), and $\beta \mathrm{ENaC}-\mathrm{Tg}$ mice were identified by PCR. Wild-type littermates served as controls in all experiments. Mice were housed in a pathogen-free animal facility and had free access to chow and water. For further details please refer to the Supplementary section. For bronchoalveolar lavage (BAL) mice were deeply anesthetized via intra-peritoneal injection of a combination of ketamine/xylazine (120 mg/kg and $16 \mathrm{mg} / \mathrm{kg}$, respectively), the trachea was cannulated and lungs were carefully lavaged twice with $800 \mu \mathrm{l}$ PBS. BRP-39 protein levels were measured in BAL supernatant using aR\&D System's ELISA. Total cell counts were determined and differential cell counts performed on cytospin preparations. Studies were performed by investigators who were blinded with respect to the genotype. We used two different invasive pulmonary function devices (both from Buxco Research Systems; Wilmington, NG): a forced maneuver system and a FinePointe RC system. Mouse pulmonary function testing was performed and analyzed as published previously [37]. All mice were anesthetized with i.p. MMF (Medetomidin, Midazolam, Fentanyl), intubated and placed in a FinePointe RC system. In a heated plethysmograph chamber, mice were ventilated at an average rate of 140 breaths per minute, and flow, mouth and esophageal pressure and heart rate were monitored to measure resistance and dynamic compliance. After an initial acclimation period of three minutes, two subsequent one-minute measurements were performed and averaged. After the resistance and compliance measures, mice were transferred to a forced pulmonary maneuvers system. Quasistatic pressure volume and fast flow volume maneuvers were run three times each and averaged to obtain forced expiratory volume at $100 \mathrm{~ms}$, forced vital capacity and chord compliance values.

\section{ELISA}

YKL-40 and BRP-39 protein levels were measured in duplicates by a commercially available, sandwich enzyme-linked immunosorbent assay (ELISA) kit (R\&D Systems) according to the manufacturer's instructions.

\section{Genotyping cohort}

Polymorphisms were genotyped in a CF population (Tables S1 and S2) to investigate the influence of single nucleotide polymorphisms (SNPs) [34] on CF lung disease. Informed written consent was obtained from all subjects included in the study or their parents, and all study methods were approved by the local ethics and by the institutional review board. For more details see ONLINE SUPPLEMENT.

\section{Statistical analysis}

Differences between the patient groups were calculated using the non-parametric Kruskal-Wallis test. When a significant difference was found, the non-parametric Mann-Whitney $U$ test was applied for two-group comparisons. Correlations were verified with Spearman rho test. Associations between SNPs and qualitative outcomes were tested by using Pearson $\mathrm{X}^{2}$ tests [35]. A $P$ value of $<0.05$ was considered to be significant. A correlation was assumed when the correlation coefficient was $>0.3$. Statistical analysis was performed with Prism 4.0 (Graph Pad Software, San Diego, CA, USA) and STATA version 8.2 for Windows (STATA Corporation, College Station, TX, USA).

\section{Results}

Increased YKL-40/BRP-39 levels in human and murine cystic fibrosis airway fluids

YKL-40 levels were significantly increased in both sputum supernatants and serum from CF patients compared to healthy 

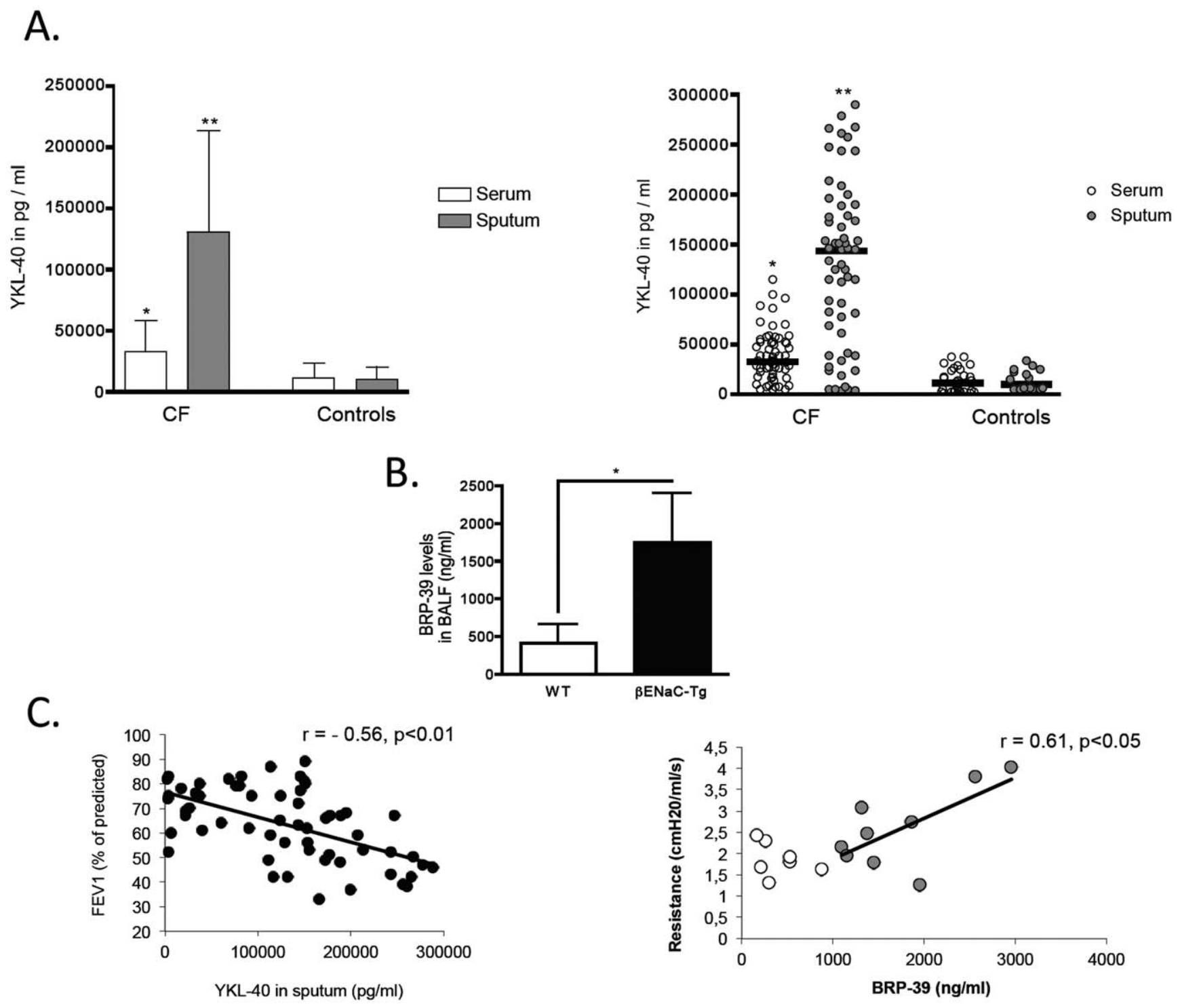

Figure 1. YKL-40 levels in human and murine CF lung disease. A. YKL-40 levels in CF patients and healthy controls YKL-40 protein levels were quantified by means of ELISA in sera and sputum supernatants from cystic fibrosis (CF) or healthy control subjects. The left graph depicts means \pm $\mathrm{SDs}$, the right scatter graph depicts individual patients with horizontal bars as medians; ${ }^{*} P<0.05 * * P<0.01$ disease group compared to the control group. Horizontal bars indicate comparisons among the disease groups. B. BRP-39 levels in murine CF-like lung disease. BRP-39 protein levels were quantified by means of ELISA in BAL fluids from $\beta E N a C-T g(n=9)$ and WT mice $(n=7)$. ${ }^{*} P<0.05$; C. YKL-40/BRP-39 airway levels and lung function in human and murine CF lung disease. Left panel: YKL-40 protein levels were quantified by means of ELISA in sputum supernatants from CF patients $(n=59)$. FEV1: Forced expiratory volume in 1 second (\% of predicted). Right panel: BRP-39 protein levels were quantified by means of ELISA in BAL fluids from $\beta E N a C-T g(n=9$, grey fill) and WT mice $(n=7$, white fill).

doi:10.1371/journal.pone.0024399.g001

control individuals (Figure 1A). Within individual CF patients, YKL-40 protein levels were consistently higher in sputum than in serum. Notably, YKL-40 levels in CF sputa and CF sera showed a broad range of detection from levels similar to healthy control levels up to 30-fold higher levels in $\mathrm{CF}$ patients compared to healthy controls (Figure 1A right graph).YKL-40 serum levels correlated positively with YKL-40 sputum levels in both CF patients $(r=0.69, p<0.01)$ and, to a lesser extent, healthy control individuals $(\mathrm{r}=0.42, \mathrm{p}<0.05)$. Sputum levels of YKL-40 correlated positively with numbers of neutrophils in sputa $(\mathrm{r}=0.74$, $\mathrm{p}<0.01)$, but not with numbers of eosinophils $(\mathrm{r}=0.13, \mathrm{p}>0.05)$, lymphocytes $(r=0.18, p>0.05)$ or macrophages $(r=0.10, p>0.05)$.
Consistent with human CF lung disease, protein levels of the murine YKL-40 homologue BRP-39 were highly increased in bronchoalveolar lavage fluid (BALF) from $\beta \mathrm{ENaC}-\mathrm{Tg}$ mice compared to BALF from WT mice (Figure 1B). Both in human CF patients as well as in murine CF lung disease, YKL-40/BRP39 airway levels correlated with airflow obstruction in pulmonary functions tests $\left(\mathrm{FEV}_{1}\right.$ and resistance, respectively, Figure $\left.1 \mathrm{C}\right)$, but not with parameters of pulmonary restriction (data not shown).

When viewed in combination, these studies demonstrate that YKL-40/BRP-39 levels are increased in CF patients and a mouse model of CF-like lung disease, and are associated with obstructive pulmonary function. 
A.

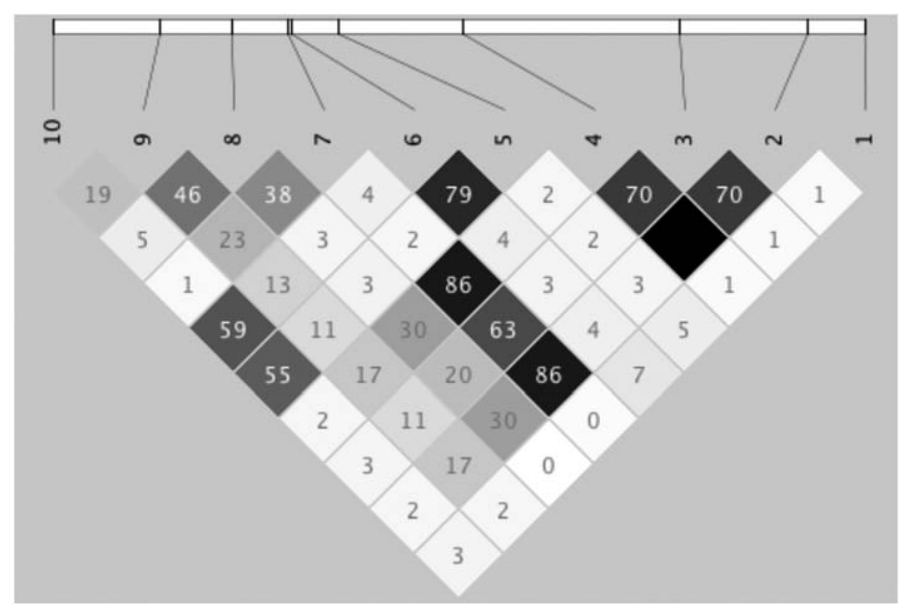

B.

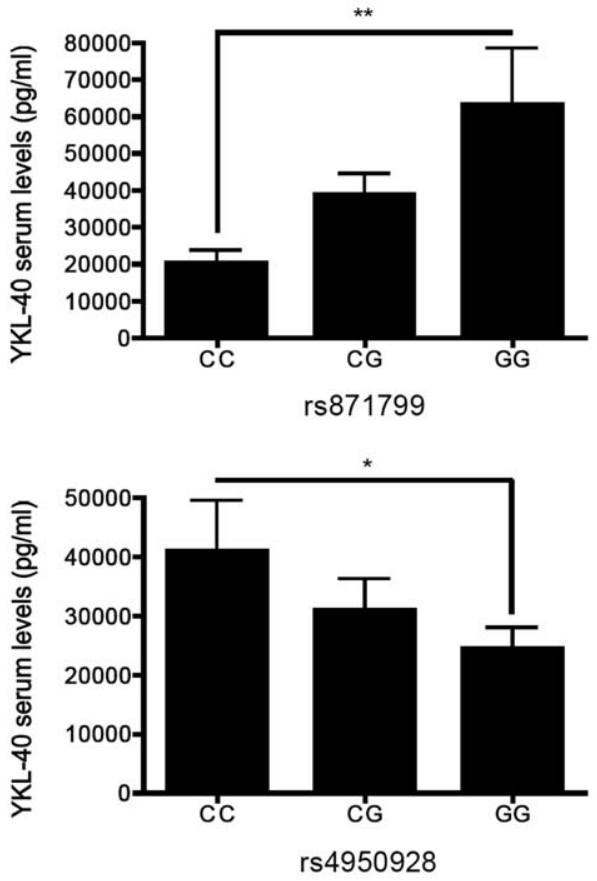

Figure 2. YKL-40 SNPs. A. Location and linkage disequilibrium $\left(R^{2}\right)$ of $Y K L-40$ polymorphisms genotyped in the CF population. B. YKL-40 serum levels in CF patients stratified for the respective rs871799 (upper panel) or the rs4950928 (lower panel) genotype. ${ }^{*} P<0.05,{ }^{* *} P<0.01$. doi:10.1371/journal.pone.0024399.g002

YKL-40 gene variants modulate YKL-40 levels and cystic fibrosis lung disease severity

Based on the finding that both YKL-40 serum and sputum levels showed a high extent of heterogeneity among CF individuals, we investigated whether $Y K L-40$ gene variants modulate YKL-40 serum levels and CF lung disease severity. Based on previous results from $Y K L-40$ SNP studies in asthmatics (11), we genotyped ten candidate SNPs tagging the $Y K L-40$ locus in a well-characterized $\mathrm{CF}$ patient cohort (Table S2 and Figure 2A). Two $T K L-40 \mathrm{SNPs}$, located in the promoter (rs871799) and in the exon 5 (rs880633) region, respectively, were found to modulate age-adjusted lung function in $\mathrm{CF}$ patients (longitudinal $\mathrm{FEV}_{1}$ age-adjusted at 20 years according to the method described previously by Schluchter et al. [19] (Table 2 and Figure 2A). Furthermore, the promoter SNPs rs871799 and rs4950928 modulated YKL-40 serum levels (Figure 2B). These studies demonstrate that $Y K L-40$ gene variants are associated with YKL-40 serum levels and pulmonary function in $\mathrm{CF}$ patients.

\section{Discussion}

CF lung disease is characterized by a vicious cycle of neutrophilic inflammation, infection and tissue remodeling. Despite an increasing body of evidence on infectious and inflammatory mechanisms contributing to CF lung disease [20],

Table 2. Association test results for $Y K L-40$ SNPs.

\begin{tabular}{|c|c|c|c|c|c|c|c|}
\hline SNP & Position & Location & Alleles & MAF FEV $1 \% @ 20$ yrs $\leq 70$ & MAF FEV $\%$ @20 yrs>70 & $\mathbf{O R}^{*}$ & Pvalue \\
\hline rs871799 & $-14,120$ & Promoter & $\mathrm{C} / \mathrm{G}$ & 0.113 & 0.192 & 0.24 & 0.043 \\
\hline rs2153101 & $-12,723$ & Promoter & T/A & 0.215 & 0.189 & 1.31 & 0.711 \\
\hline rs946263 & $-9,630$ & Promoter & $A / G$ & 0.144 & 0.138 & 0.73 & 1.000 \\
\hline rs4950929 & $-4,374$ & Promoter & $\mathrm{T} / \mathrm{G}$ & 0.215 & 0.200 & 0.82 & 1.000 \\
\hline rs6691378 & $-1,371$ & Promoter & $\mathrm{G} / \mathrm{A}$ & 0.136 & 0.154 & 1.78 & 0.469 \\
\hline rs10399805 & -247 & Promoter & $\mathrm{G} / \mathrm{A}$ & 0.156 & 0.178 & 1.11 & 1.000 \\
\hline rs4950928 & -131 & Promoter & C/G & 0.226 & 0.183 & 1.09 & 1.000 \\
\hline rs1538372 & $+1,220$ & Intron 2 & $\mathrm{G} / \mathrm{A}$ & 0.371 & 0.337 & 0.94 & 1.000 \\
\hline rs880633 & $+2,951$ & Exon 5 & $\mathrm{~T} / \mathrm{C}$ & 0.419 & 0.522 & 0.46 & 0.016 \\
\hline rs2275352 & $+5,573$ & Intron 7 & $\mathrm{G} / \mathrm{A}$ & 0.188 & 0.154 & 0.71 & 1.000 \\
\hline
\end{tabular}

*recessive model; MAF, minor allele frequency; FEV1\%@20 yrs, age-adjusted (at 20 years) longitudinal forced expiratory volume (FEV 1 ) (19); OR, odds ratio. doi:10.1371/journal.pone.0024399.t002 
host-derived factors that modulate CF lung disease severity and may serve as biomarkers are yet poorly defined. The CLP YKL-40 is induced at sites of inflammation, and previous studies suggested a role for this ancient glycoprotein as biomarker and potential therapeutic target in asthma $[8,18]$ and COPD [9]. It remained, however, elusive whether the accumulation of YKL-40 is specific for these disease conditions or whether YKL-40 increase reflects chronic pulmonary inflammation. In particular, the role of YKL40 in CF lung disease has not been characterized so far. Here we demonstrate that YKL-40 protein levels are highly increased in the airways of patients and mice with CF lung disease and correlate with neutrophilic inflammation and airflow obstruction. Similar as in asthma, YKL-40 serum levels in CF patients were regulated genetically by promoter SNPs [11].

Previous studies found increased YKL-40protein levels and expression, respectively, in the circulation and lung from patients with severe asthma [8] and COPD [9]. Recently, YKL-40 has been described to play a role in hyperoxia-induced acute lung injury [10]. YKL-40 has also been implicated in a variety of nonpulmonary inflammatory diseases, such as rheumatoid arthritis [12], systemic sclerosis [13], myocardial infarction [14], meningitis[15], diabetes [16] and cancer[17]. We found that increased YKL-40 levels correlated with neutrophilic cellular infiltrate in CF patients. This finding may correspond to the results from Chupp et al. demonstrating that YKL-40 serum levels were particularly increased in severe asthma, a disease phenotype frequently featuring a more pronounced neutrophilic than eosinophilic airway infiltrate associated with corticosteroid resistance. Given this latter study and our present data, it remains to be investigated in future studies whether increased YKL-40 serum/airway levels are restricted to asthma subtypes with a pronounced neutrophilic inflammation.

The question arises which factors underlie the highly increased YKL-40 levels in CF patients. We speculate that YKL-40 levels in CF reflect the extent of neutrophilic airway inflammation rather than being modulated directly by the genetic CF defect (Cystic Fibrosis Transmembrane Conductance, CFTR). Neutrophils have been reported to store YKL-40 intracellularly in their secondary granules [21] and CF airway neutrophils were consistently found to express CD66b [23], indicating post-activation and release of secondary granules. YKL-40 protein levels in our study were highest in CF sputa, where numerous activated neutrophils accumulate, whereas in $\mathrm{CF}$ sera only moderately increased levels were found. At rising YKL-40 airway levels, the CLP may leak out into the circulation, explaining the increased levels found in serum of CF patients. Nevertheless, GFTR deficient neutrophils may intrinsically release more YKL-40 than control cells, a hypothesis that should be addressed in future studies.

The promoter SNP rs4950928 in the $Y K L-40$ gene was previously found to modulate YKL-40 serum levels and asthmatic lung disease severity [11]. Our studies demonstrated that two $Y K L-$ 40 SNPs (rs871799 and rs880633), located in the promoter region or exon 5, respectively, modulated age-adjusted lung function [19] in $\mathrm{CF}$ patients. Consistent with the previous study in asthmatics [11], we found that rs4950928 affected YKL-40 serum levels, but differently in our CF cohort, rs4950928 variants had no association with lung function in CF patients. Besides rs4950928, we identified a second promoter SNP (rs871799) that affected YKL-40 serum levels in CF patients. Based on previously published studies [11] and the herein described genetic studies, we suggest that at least two distinct promoter SNPs modulate YKL-40 serum levels in CF patients. We further speculate that rs871799 could be involved in both regulating YKL-40 serum levels and modulating FEV1, while rs880633 may affect YKL-40 functionality that, in turn, may modulate pulmonary CF disease (FEV1), without regulating YKL-40 expression and protein (serum) levels. Beyond that, the impact of $Y K L-40$ SNPs on lung function might depend on the type of pulmonary disease pathology (Th2-driven asthmatic versus CF lung disease). Within asthmatics, severe neutrophil-associated asthma may represent a distinct entity featuring increased YKL-40 levels [24,25].

Despite significant processes in the field of chitinase-like proteins in the last years, including generation and characterization of transgenic mouse models, the biological and pathophysiological function of secreted YKL-40 in pulmonary diseases remains enigmatic [26-28]. Based on previous studies, using a genetic brp39 knock-out and a humanized YKL-40 transgenic overexpressing mouse, demonstrating that YKL-40/BRP-39 plays a role in tissue remodeling, cell death pathway regulation and airway obstruction [29],we speculate that released YKL-40 contributes to the cellular homeostasis and tissue remodeling, thereby modulating pulmonary function and inflammation in CF. However, additional studies focused on the functionality of YKL-40 in the CF microenvironment are required to understand the pathophysiological mechanisms linking YKL-40 and CF airway inflammation.

In summary, our studies demonstrated increased airway levels of the chitinase-like protein YKL-40 in CF patients compared to control individuals. This finding in $\mathrm{CF}$ patients could be corroborated by studies in a CF-like murine disease model. In both human and murine CF airway fluids, YKL-40/BRP-39 levels correlated with lung function, suggesting that increased YKL-40/ BRP-39 levels may have an impact on airway obstruction in CF patients. These results suggest YKL-40 levels in sputum as potential biomarker of neutrophilic airway inflammation in $\mathrm{CF}$.

\section{Supporting Information}

Table S1 GF genotyping patient cohort. \# no FEV1 data available for 20 patients; * predicted FEV1 values for CF patients at age of 20 years, as previously reported (19); § no microbiological data available for 18 patients.

(DOC)

Table S2 Primers for genotyping YKL-40 tagging SNPs. dbSNP IDs (www.ncbi.nlm.nih.gov/SNP), SNP positions of genotyped SNPs (counted from the first nucleotide of the initiation codon as +1), and primers used for matrix-assisted laser desorption/ionization time-of-flight mass spectrometry (MALDITOF).

(DOC)

\section{Methods S1 Supplementary methods. (DOG)}

\section{Acknowledgments}

We gratefully acknowledge the expert technical assistance of Stephanie Hirtz and Jolanthe Schatterny in breeding and genotyping of experimental animals.

\section{Author Contributions}

Conceived and designed the experiments: O. Eickelberg MAM DH. Performed the experiments: AH MSDK PL EK CG MK BK IM. Contributed reagents/materials/analysis tools: PL EK CG MK BK EE O. Eickmeier SZ NR MG. Wrote the paper: DH MAM AH. Analyzed the human data: AH MSDK IM DH. Analyzed the murine data: ZZ AÖY AB. 


\section{References}

1. Davis PB, Drumm M, Konstan MW (1996) Cystic fibrosis. Am J Respir Crit Care Med 154: 1229-1256.

2. Hartl D, Latzin P, Hordijk P, Marcos V, Rudolph C, et al. (2007) Cleavage of cxcr1 on neutrophils disables bacterial killing in cystic fibrosis lung disease. Nat Med 13: 1423-1430.

3. Bleau G, Massicotte F, Merlen Y, Boisvert C (1999) Mammalian chitinase-like proteins. EXS 87: 211-221.

4. Rejman JJ, Hurley WL (1988) Isolation and characterization of a novel 39 kilodalton whey protein from bovine mammary secretions collected during the nonlactating period. Biochem Biophys Res Commun 150: 329-334.

5. Shackelton LM, Mann DM, Millis AJ (1995) Identification of a 38-kda heparinbinding glycoprotein (gp38k) in differentiating vascular smooth muscle cells as a member of a group of proteins associated with tissue remodeling. J BiolChem 270: $13076-13083$.

6. Hakala BE, White C, Recklies AD (1993) Human cartilage gp-39, a major secretory product of articular chondrocytes and synovial cells, is a mammalian member of a chitinase protein family. J Biol Chem 268: 25803-25810.

7. Recklies AD, White $\mathrm{C}$, Ling $\mathrm{H}$ (2002) The chitinase 3-like protein human cartilage glycoprotein 39 (hc-gp39) stimulates proliferation of human connectivetissue cells and activates both extracellular signal-regulated kinase- and protein kinase b-mediated signalling pathways. Biochem J 365: 119-126.

8. Chupp GL, Lee CG, Jarjour N, Shim YM, Holm CT, et al. (2007) A chitinaselike protein in the lung and circulation of patients with severe asthma. N Engl J Med 357: 2016-2027.

9. Letuve S, Kozhich A, Arouche N, Grandsaigne M, Reed J, et al. (2008) Ykl-40 is elevated in patients with chronic obstructive pulmonary disease and activates alveolar macrophages. J Immunol 181: 5167-5173.

10. Sohn MH, Kang MJ, Matsuura H, Bhandari V, Chen NY, et al. (2010) The chitinase-like proteins breast regression protein-39 and ykl-40 regulate hyperoxia-induced acute lung injury. Am J Respir Crit Care Med 182: 918-928.

11. Ober C, Tan Z, Sun Y, Possick JD, Pan L, et al. (2008) Effect of variation in chi3l1 on serum ykl-40 level, risk of asthma, and lung function. N Engl J Med 358: 1682-1691.

12. Volck B, Johansen JS, Stoltenberg M, Garbarsch C, Price PA, et al. (2001) Studies on ykl-40 in knee joints of patients with rheumatoid arthritis and osteoarthritis. Involvement of ykl-40 in the joint pathology. Osteoarthritis Cartilage 9: 203-214

13. Nordenbaek C, Johansen JS, Halberg P, Wiik A, Garbarsch C, et al. (2005) High serum levels of ykl-40 in patients with systemic sclerosis are associated with pulmonary involvement. Scand J Rheumatol 34: 293-297.

14. Nojgaard C, Host NB, Christensen IJ, Poulsen SH, Egstrup K, et al. (2008) Serum levels of ykl-40 increases in patients with acute myocardial infarction. Coron Artery Dis 19: 257-263.

15. Ostergaard C, Johansen JS, Benfield T, Price PA, Lundgren JD (2002) Ykl-40 is elevated in cerebrospinal fluid from patients with purulent meningitis. Clin Diagn Lab Immunol 9: 598-604.

16. Nielsen AR, Erikstrup C, Johansen JS, Fischer CP, Plomgaard P, et al. (2008) Plasma ykl-40 - a bmi-independent marker of type 2 diabetes. Diabetes 57: 3078-3082.

17. Johansen JS, Jensen BV, Roslind A, Price PA (2007) Is ykl-40 a new therapeutic target in cancer? Expert Opin Ther Targets 11: 219-234.

18. Hartl D, Lee CG, Da Silva CA, Chupp GL, Elias JA (2009) Novel biomarkers in asthma: Chemokines and chitinase-like proteins. Curr Opin Allergy Clin Immunol 9: 60-66.
19. Schluchter MD, Konstan MW, Drumm ML, Yankaskas JR, Knowles MR (2006) Classifying severity of cystic fibrosis lung disease using longitudinal pulmonary function data. Am J Respir Crit Care Med 174: 780-786.

20. Banner KH, De Jonge H, Elborn S, Growcott E, Gulbins E, et al. (2009) Highlights of a workshop to discuss targeting inflammation in cystic fibrosis. J Cyst Fibros 8: 1-8.

21. Volck B, Price PA, Johansen JS, Sorensen O, Benfield TL, et al. (1998) Ykl-40, a mammalian member of the chitinase family, is a matrix protein of specific granules in human neutrophils. Proc Assoc Am Physicians 110: 351-360.

22. Koller B, Kappler M, Latzin P, Gaggar A, Schreiner M, et al. (2008) Tlr expression on neutrophils at the pulmonary site of infection: Tlr $1 / \mathrm{tl} 2$-mediated up-regulation of tlr5 expression in cystic fibrosis lung disease. J Immunol 181: 2753-2763.

23. Tirouvanziam R, Gernez Y, Conrad CK, Moss RB, Schrijver I, et al. (2008) Profound functional and signaling changes in viable inflammatory neutrophils homing to cystic fibrosis airways. Proc Natl Acad Sci U S A 105: 4335-4339.

24. Moore WC, Meyers DA, Wenzel SE, Teague WG, Li H, et al. (2010) Identification of asthma phenotypes using cluster analysis in the severe asthma research program. Am J Respir Crit Care Med 181: 315-323.

25. Wenzel SE (2004) Phenotypes in asthma: Useful guides for therapy, distinct biological processes, or both? Am J Respir Crit Care Med 170: 579-580.

26. Elias JA, Homer RJ, Hamid Q Lee CG (2005) Chitinases and chitinase-like proteins in $\mathrm{t}(\mathrm{h}) 2$ inflammation and asthma. J Allergy Clin Immunol 116 : 497-500.

27. Lee CG (2009) Chitin, chitinases and chitinase-like proteins in allergic inflammation and tissue remodeling. Yonsei Med J 50: 22-30.

28. Junker N, Johansen JS, Andersen CB, Kristjansen PE (2005) Expression of ykl40 by peritumoral macrophages in human small cell lung cancer. Lung Cancer 48: 223-231.

29. Lee GG, Hartl D, Lee GR, Koller B, Matsuura H, et al. (2009) Role of breast regression protein 39 (brp-39)/chitinase 3 -like-1 in th2 and il-13-induced tissue responses and apoptosis. J Exp Med 206: 1149-1166.

30. Hartl D, Lehmann N, Hoffmann F, Jansson A, Hector A, et al. (2008) Dysregulation of innate immune receptors on neutrophils in chronic granulomatous disease. J Allergy Clin Immunol 121: 375-382.

31. Standardization of spirometry - 1994 update (1995) Am J Respir Crit Care Med 152: 1107-1136.

32. Standards for the diagnosis and care of patients with chronic obstructive pulmonary disease (copd) and asthma (1987) Am Rev Respir Dis 136: 225-244.

33. Hector A, Jonas F, Kappler M, Feilcke M, Hartl D, et al. (2009) Novel method to process cystic fibrosis sputum for determination of oxidative state. Respiration 80: $393-400$.

34. Kormann MS, Carr D, Klopp N, Illig T, Leupold W, et al. (2005) G-proteincoupled receptor polymorphisms are associated with asthma in a large german population. Am J Respir Crit Care Med 171: 1358-1362.

35. Sasieni PD (1997) From genotypes to genes: Doubling the sample size. Biometrics 53: 1253-1261

36. Mall M, Grubb BR, Harkema JR, O'Neal WK, Boucher RC (2004) Increased airway epithelial nat absorption produces cystic fibrosis-like lung disease in mice. Nat Med 10: 487-493.

37. Vanoirbeek JA, Rinaldi M, De Vooght V, Haenen S, Bobic S, et al. (2010) Noninvasive and invasive pulmonary function in mouse models of obstructive and restrictive respiratory diseases. Am J Respir Cell Mol Biol 42: 96-104. 